\title{
Influence of mobilization and weight bearing on in-hospital outcome in geriatric patients with hip fractures
}

\author{
Manuel Baer, Valentin Neuhaus*, Hans Christoph Pape, and Bernhard Ciritsis \\ Division of Trauma Surgery, Department of Surgery, University Hospital Zurich, University of Zurich, Zurich, Switzerland
}

Received 28 October 2018, Accepted 28 January 2019, Published online 28 February 2019

\begin{abstract}
Introduction: Early recovery of mobilization after a fracture of the hip is associated with improved longterm ability to walk, lower complication rates, and mortality. In this context, early mobilization and full weight bearing are favorable. The aim of this study was (1) to analyze the influence of time between operation and first mobilization on in-hospital outcome and (2) the influence of early mobilization, full weight bearing, and ASA on pain, mobility of the hip, and ability to walk during the in-hospital phase of recovery.

Methods: This is a retrospective in-hospital study of 219 patients aged 70 years or older who were treated with surgery after a hip fracture. Data were collected by a review of medical records. The outcomes were mortality, complications, length of stay, and the Merle d'Aubigné score which evaluates pain, mobility of the hip, and ability to walk. Factors were sought in bivariate and multivariate analyses.

Results: A shorter time between operation and first mobilization was significantly associated with lower in-hospital mortality and complications. Early mobilization (within $24 \mathrm{~h}$ after the operation) and full weight bearing had no influence on pain, mobility of the hip, and ability to walk as well as length of stay in our cohort. Fracture type and treatment influenced mobility of the hip, while age as well as physical health status affected the ability to walk.

Discussion: Patients with femoral neck fractures, respectively after total hip arthroplasty, had less pain and showed better mobility of the hip and ability to walk during hospitalization than patients with trochanteric fractures; these results were irrespective of early vs. late mobilization and full vs. partial weight bearing. Foremost, a shorter time between operation and first mobilization is associated with lower complication and mortality rates.
\end{abstract}

Key words: Hip fracture, Mobilization, Weight bearing, Complications, Mortality, In-hospital outcome.

\section{Introduction}

The increase in life expectancy in the past few decades has led to a substantial increase in fragility fractures. Especially, hip fractures are common and serious injuries of elderly people that lead to loss of mobility and independency and result in significant socioeconomic consequences $[1,2]$. Elderly patients with hip fractures often present with comorbidities and frequently suffer complications during their hospital stay [3]. In addition, patients become further debilitated by pain, loss of mobility, and quality of life [1]. Although the main goals of the treatment of hip fractures are early mobilization and return to previous social activities, many patients never recover to their prefracture functional level [4,5].

Early recovery of mobilization has not only a significant impact on short-term results, such as lower complication rates and shorter length of stay, but also results in better long-term outcomes such as higher autonomy and reduced mortality [6-11].

\footnotetext{
*Corresponding author: mr. manuel. baer@gmail. com
}

Kristensen et al. showed that after adjustment for important pre-surgery variables, the mobility status at discharge is a predictor for long-term mortality [12]. Multiple factors (such as age, gender, social status, pre-fracture ambulatory level, and comorbidities) have been detected to have an influence on the functional outcome; however they can rarely be modified [13-17]. At the same time, potentially modifiable factors (full weight bearing, early mobilization, pain management) seem less studied to the best of our knowledge.

A multidisciplinary postoperative approach and early ambulation have been identified to increase functional outcome at discharge and enhanced performance in activities of daily living after hip fracture [3,7,18-21]. In this context, the effect of postoperative weight bearing is still controversial although full weight bearing seems to be favored [22-25].

The purpose of this study was (1) to analyze the influence of time between operation and first mobilization on in-hospital mortality as well as complications and (2) the association between early and late mobilization, full or partial weight bearing as well as American Society of Anesthesiologist Physical 
Status classification [26] (ASA) on pain, mobility of the hip, and ability to walk while controlling for type of fracture and treatment in geriatric patients with hip fractures.

\section{Materials and methods}

\section{Study subjects}

This retrospective observational study was approved by the local ethics committee (KEK-ZH-Nr. 2011-0382), and written informed consent was obtained from all patients.

Patients meeting the following criteria were included: (a) age over 70 years; (b) diagnosis of a femoral neck or trochanteric fracture treated with intramedullary nail (Gamma 3 Nail-Stryker ${ }^{\circledR}$, Stryker Corporation, Kalamazoo, MI), total or partial hip prosthesis at our institution; (c) complete Merle d'Aubigné score [27] at discharge; (d) reported/documented ASA score, postsurgical treatment with either partial or full weight bearing, and time to first mobilization. Exclusion criteria were: (a) pathological fractures; (b) polytraumatized patients; (c) patients already hospitalized in a different department in our hospital; (d) non-operative treatment trial; (e) periprosthetic fracture; and (f) subtrochanteric fractures. A total of 294 patients with a hip fracture from a level I trauma center between 2011 and 2017 were reviewed. The final study cohort consisted of 219 patients.

\section{Surgical procedures}

Patients receiving an intramedullary gamma nail were placed in supine position on the fracture table and closed reduction of the fracture was obtained. Traction was applied to the fracture, keeping the leg straight and then rotated $10-15^{\circ}$ internally to complete the reduction of the fracture. Standard skin incisions were made after identifying the greater trochanter. A reamer was used to open the medullary canal, the nail was inserted (180 mm length and $130^{\circ}$ neck-shaft-angle), and the femoral head lag as well as femoral shaft locking screws were placed using the targeting device. After removing the targeting device, the final position of the implant was verified using the image intensifier.

Total and partial hip prostheses were done in supine position on an orthopedic table with a mobile leg positioner. Arthrotomy was done by a minimal anterolateral access following osteotomy of the femoral neck and extraction of the femoral head. Following standard surgical procedures in hip prosthesis, the acetabulum was exposed followed by reaming and placing of the acetabular implant in the correct angle under image intensifier. After positioning the femur in hyperextension, adduction, and external rotation, the medullary canal of the proximal femur was opened and the stem was placed in both total and partial hip replacements. Using the image intensifier, positioning was controlled intraoperative.

\section{Review of medical records}

An orthopedic medical doctor reviewed the medical records, anesthesiological and surgical reports, and reports from physiotherapists as well as nurses. The following parameters were collected: (a) gender; (b) age; (c) diagnosis; (d) type of treatment; (e) Merle d'Aubigné score with its three modalities; (f) ASA score; (g) full or partial weight bearing; (h) time interval between surgery and first mobilization; (i) complications; (j) mortality and (k) length of stay.

\section{Outcome parameters}

For the first research question, the outcomes were (a) inhospital mortality, (b) length of stay, and (c) occurrence of the following complications during hospitalization: deep vein thrombosis, pulmonary embolism, urinary tract infection, decubitus, gastroduodenal ulcers, pseudomembranous colitis, urosepsis, electrolyte dysregulation requiring treatment, delirium, renal insufficiency, pneumonia including aspiration pneumonia, heart and respiratory insufficiency, myocardial infarction, ileus, wound infection, transient ischemic attack or stroke, and death.

For the second research question (only patients discharged alive), the outcome was assessed at the end of hospitalization with the Merle d'Aubigné score which evaluated pain, mobility of the hip, and ability to walk on a scale of 0-6 for each item, where 0 indicated the worst and 6 the best outcome of the patient. The total minimum score was 0 and the maximum was 18 [27].

\section{Pain}

The seven subgroups were the following: 0: Pain is intense and permanent; 1: Pain is severe, even at night; 2 : Pain is severe when walking and prevents activity; 3: Pain is tolerable with limited activity; 4: Mild pain when walking and the pain disappears with rest; 5: Pain is mild and inconsistent, normal activity is possible; 6: No pain.

\section{Mobility of the hip}

The seven subgroups were the following: 0: Ankylosis with bad position of the hip; 1: No movement possible; 2: Flexion $<40^{\circ}$; 3: Flexion $40-60^{\circ}$; 4: Flexion $60-80^{\circ}$, patient can reach his foot; 5: Flexion $80-90^{\circ}$ and abduction $15-30^{\circ}$; 6: Flexion $>90^{\circ}$ and abduction $>30^{\circ}$.

\section{Ability to walk}

The seven subgroups were the following: 0: The patient is not able to walk; 1: The patient is bedridden or uses canes or crutches and personal help to go to the bathroom; 2: The patient can walk only with crutches or walking frame; 3 : The patient can walk with canes; 3: The patient can walk with one cane for less than an hour, without a can only with much difficulties; 4: The patient can walk for a long period ( $>1 \mathrm{~h}$ ) with a cane, short time without cane but with a limp; 5: The patient can walk without a walking aid but with a slight limp; 6: Normal walking abilities.

\section{Independent variables and confounders}

Independent variables were age, gender, fracture type as well as fracture treatment. Confounders were the ASA score, 
full or partial weight bearing, and time interval between surgery and first mobilization.

\section{ASA}

An anesthesiologist preoperatively classified the patients undergoing surgery by the American Society of Anesthesiologist Physical Status classification (ASA) and documented it in the anesthesiologic report. The physical status were: Class I: a normally healthy patient; Class II: a patient with mild systemic disease; Class III: a patient with severe systemic disease that is not incapacitating; Class IV: a patient with an incapacitating systemic disease that is a constant threat to life; Class V: a moribund patient who is not expected to survive for $24 \mathrm{~h}$ with or without operation. No patient was classified ASA V. For statistical analysis, the patients were dichotomized into ASA I/II and ASA III/IV.

\section{Weight bearing}

The postoperative level of weight bearing was determined by the surgeon. Because not all patients were able to follow postsurgical weight bearing according to the surgeons' prescription, there were discrepancies between surgical reports and reports from physiotherapists. The actual weight bearing performed by the patient was used as the postoperative level of weight bearing. Patients were mobilized either with full or partial weight bearing.

\section{Mobilization}

For the first research question, patients were classified into three categories by the time between the operation and first mobilization: (a) within $24 \mathrm{~h}$, (b) between 24 and $48 \mathrm{~h}$, (c) after $48 \mathrm{~h}$.

For the second research question, early mobilization was defined as first mobilization of the patient within $24 \mathrm{~h}$ after surgery and late mobilization after $24 \mathrm{~h}$.

\section{Statistical analysis}

Standard descriptive statistical analyses were performed using SPSS software package (SPSS version 23, International Business Machines Corp., Armonk, NY). Continuous data were presented as mean values with standard deviation (SD), were examined for normal distribution by exact KolmogorovSmirnov test, and compared with either $t$-test or Mann-Whitney $U$-test. Differences in frequencies of categorical data were assessed by chi-squared test or Fisher's exact test, depending on the number of expected cases per group. For the first research question, only variables, which were significant or nearly significant $(p<0.1)$ in bivariate analysis, were entered into a regression analysis with the main primary outcome complications. Due to a low number of deaths, no regression analysis was done for mortality. For the second research question, all independent and confounding variables were entered into a linear regression analysis with the main primary outcome parameters as well as the Merle d'Aubigné score, and length of stay. level.

A $p$-value of 0.05 was chosen as the significance cut-off

\section{Results}

\section{Mortality}

The overall in-hospital mortality rate was $7.3 \%$ (Table 1). In bivariate analysis, ASA as well as time between operation and first mobilization were associated with mortality ( $p=$ 0.001 and $p<0.001)$.

\section{Complications}

The overall complications rate, including death, was $39.7 \%$. Gender, ASA, and time between operation and first mobilization were associated with in-hospital complications ( $p=$ $0.033, p<0.001$, and $p=0.023$ ). In multivariate analysis, a higher ASA score and longer time between operation and first immobilization (less than $24 \mathrm{~h}$ vs. longer than $48 \mathrm{~h}$ ) were significant predictors for a higher complication rate (Table 2).

\section{Pain}

The overall pain was $4.0 \pm 0.9$ (Table 3 ). Pain was significantly higher (lower score) in trochanteric fracture patients than in patients with femoral neck fractures $(p<0.001)$. The level of pain in patients treated with intramedullary nail was significantly higher compared to patients with total and partial hip replacements $(p<0.001$ and $p=0.004)$. No predictors for pain were found in multivariate analysis (Table 4).

\section{Mobility of the hip}

The overall mobility was $4.4 \pm 0.8$. Mobility at the end of hospitalization was significantly better in femoral neck fracture patients than in patients with trochanteric fractures $(p=0.008)$. Patients treated with a total hip replacement were significantly better mobilized than patients after intramedullary nailing or partial hip replacement $(p<0.001$ and $p=0.008$ ). In multivariate analysis, fracture type and fracture treatment were significant: femoral neck as well as total hip replacement were associated with higher mobility of the hip (Table 5).

\section{Ability to walk}

The overall ability to walk was $1.5 \pm 0.9$. At discharge, femoral neck fracture patients and patients classified with ASA I/II had a significantly higher score for ability to walk ( $p=0.016$ and $p=0.011$ ). Patients treated with total hip replacement had a better ability to walk than patients with an intramedullary nail or partial hip replacement $(p<0.001$ and $p=0.002$ ). In multivariate analysis, younger age as well as lower ASA score were found as predictors for ability to walk (Table 6). 
Table 1. Overview.

\begin{tabular}{|c|c|c|c|c|c|c|c|}
\hline & \multicolumn{2}{|c|}{$\begin{array}{c}\text { Total } \\
(n=219)\end{array}$} & \multicolumn{2}{|c|}{$\frac{\text { Mortality }}{(n=16,7.3 \%)}$} & \multicolumn{2}{|c|}{$\frac{\text { Complications }}{(n=87,39.7 \%)}$} & \multirow{2}{*}{$\begin{array}{l}\frac{\text { Length of stay }}{(9.6( \pm 5.3))} \\
\text { Days }( \pm S D)\end{array}$} \\
\hline & $n$ & $\%$ & $\bar{n}$ & $\%$ & $\bar{n}$ & $\%$ & \\
\hline \multicolumn{8}{|l|}{$\overline{\text { Gender }}$} \\
\hline Male & 70 & 32 & 8 & 11.4 & 35 & 50 & $9.2( \pm 4.9)$ \\
\hline Female & 149 & 68 & 8 & 5.4 & 52 & 34.9 & $10.7( \pm 6.0)$ \\
\hline \multicolumn{8}{|l|}{ Fracture type } \\
\hline Trochanteric & 157 & 72 & 11 & 7 & 63 & 40.1 & $9.3( \pm 5.3)$ \\
\hline Femoral neck & 62 & 28 & 5 & 8.1 & 24 & 38.7 & $10.7( \pm 5.1)$ \\
\hline \multicolumn{8}{|l|}{ Fracture treatment } \\
\hline Intramedullary nail & 158 & 72 & 11 & 7 & 63 & 39.9 & $9.2( \pm 5.3)$ \\
\hline Total hip replacement & 35 & 16 & 2 & 5.7 & 13 & 37.1 & $10.8( \pm 5.2)$ \\
\hline Partial hip replacement & 26 & 11 & 3 & 11.5 & 11 & 42.3 & $10.6( \pm 5.1)$ \\
\hline \multicolumn{8}{|l|}{ Mobilization } \\
\hline Early & 132 & 60 & 3 & 2.4 & 42 & 33.6 & $9.5( \pm 5.4)$ \\
\hline Late & 87 & 40 & 13 & 13.8 & 45 & 47.9 & $10( \pm 5.2)$ \\
\hline \multicolumn{8}{|l|}{ Time to first mobilization } \\
\hline$<24 \mathrm{~h}$ & 124 & 56 & 3 & 2.4 & 42 & 33.9 & $9.5( \pm 5.4)$ \\
\hline $24-48 \mathrm{~h}$ & 77 & 35 & 6 & 7.8 & 33 & 42.9 & $10.5( \pm 5.3)$ \\
\hline$>48 \mathrm{~h}$ & 18 & 8 & 7 & 38.9 & 12 & 66.7 & $7.5( \pm 3.8)$ \\
\hline \multicolumn{8}{|l|}{ Weight bearing } \\
\hline Full & 153 & 70 & 8 & 5.2 & 58 & 37.9 & $9.4( \pm 5.3)$ \\
\hline Partial & 66 & 30 & 8 & 12.1 & 29 & 43.9 & $10.3( \pm 5.2)$ \\
\hline \multicolumn{8}{|l|}{ ASA } \\
\hline I/II & 83 & 38 & 0 & 0 & 19 & 22.9 & $9.7( \pm 4.9)$ \\
\hline III/IV & 136 & 62 & 16 & 11.8 & 68 & 50 & $9.7( \pm 5.6)$ \\
\hline
\end{tabular}

ASA, American Society of Anesthesiologist Physical Status classification; $n$, numbers.

Table 2. Predictors for complications.

\begin{tabular}{lcccc}
\hline & Sig. & $\operatorname{Exp}(B)$ & \multicolumn{2}{c}{$95 \%$ CI } \\
\cline { 4 - 5 } & & & Lower & Upper \\
\hline Gender (male) & 0.128 & 1.599 & 0.874 & 2.929 \\
ASA III/IV vs. I/II & 0.001 & 2.946 & 1.568 & 5.534 \\
Time to first mobilization & & & & \\
$\quad<24$ h vs >48 h & 0.031 & 3.290 & 1.119 & 9.679 \\
24-48 h vs >48 h & 0.471 & 1.252 & 0.680 & 2.306 \\
\hline
\end{tabular}

Dependent variable: Complications.

Predictors: (Constant), Gender, ASA, Time to first mobilization.

\section{Merle d'Aubigné}

The overall Merle d'Aubigné score at discharge was $10 \pm 1.9$. In bivariate analysis, patients with a) femoral neck fracture or b) with a total hip replacement were associated with a higher (better) Merle d'Aubigné score $(p<0.001$ and $p=0.013$ ). In multivariate analysis, femoral neck fracture was a significant predictor for a higher Merle d'Aubigné score (Table 7).

\section{Length of stay}

The overall length of stay was $9.8 \pm 5.1$ days. Female patients, femoral neck fractures, partial weight bearing, and treatment with total or partial hip replacements were significantly associated with a longer in-hospital stay $(p=0.015, p=0.021, p=0.027, p=0.038)$. In multivariate analysis, gender was the only significant predictor for length of stay (Table 8).

\section{Discussion}

Early mobilization and full weight bearing in geriatric patients with hip fractures are usually associated with a faster and uneventful recovery. The aim of this study was (1) to analyze the influence of time between operation and first mobilization on in-hospital mortality as well as complications and (2) the influence of early mobilization, full weight bearing, and healthy physical status on in-hospital pain, mobility of the hip, and ability to walk in geriatric patients with hip fractures. First, a shorter time between operation and first mobilization was significantly associated with lower in-hospital mortality and complications. Second, early mobilization and full weight bearing had no influence on pain, mobility of the hip, and ability to walk as well as length of stay in our cohort. Fracture type and treatment mainly influenced mobility of the hip, and age as well as physical health status impacted the ability to walk.

There are several limitations of the study. First, it is a retrospective, observational study; second, scores were obtained by a review of medical records and reports; third, only in-hospital follow-up was analyzed; and last, the limited number of patients. 
Table 3. Overview.

\begin{tabular}{|c|c|c|c|c|c|c|}
\hline & Total & Pain & Mobility & Ability to walk & Merle d'Aubigné & Length of stay \\
\hline & $n=203$ & $4.0( \pm 0.9)$ & $4.4( \pm 0.8)$ & $1.5( \pm 0.9)$ & $10.0( \pm 1.9)$ & $9.8( \pm 5.1)$ \\
\hline Age $(y)$ & $83(7.1)$ & - & - & - & - & - \\
\hline \multicolumn{7}{|l|}{ Gender } \\
\hline Male & $62(30 \%)$ & $4.1( \pm 1.0)$ & $4.4( \pm 0.9)$ & $1.6( \pm 0.9)$ & $10.1( \pm 1.9)$ & $9.2( \pm 4.7)$ \\
\hline Female & $141(70 \%)$ & $4.1( \pm 1.1)$ & $4.4( \pm 0.8)$ & $1.6( \pm 1.0)$ & $10.1( \pm 2.0)$ & $11.3( \pm 6.1)$ \\
\hline \multicolumn{7}{|l|}{ Fracture type } \\
\hline Trochanteric & $146(72 \%)$ & $3.9( \pm 0.9)$ & $4.3( \pm 0.8)$ & $1.5( \pm 0.9)$ & $9.7( \pm 1.7)$ & $9.4( \pm 5.2)$ \\
\hline Femoral neck & $57(28 \%)$ & $4.6( \pm 1.1)$ & $4.6( \pm 0.8)$ & $1.8( \pm 1.0)$ & $11.1( \pm 2.0)$ & $11.0( \pm 5.1)$ \\
\hline \multicolumn{7}{|l|}{ Fracture treatment } \\
\hline Intramedullary nail & $147(72 \%)$ & $3.9( \pm 0.9)$ & $4.3( \pm 0.8)$ & $1.5( \pm 0.9)$ & $9.7( \pm 1.7)$ & $9.4( \pm 5.2)$ \\
\hline Total hip replacement & $33(16 \%)$ & $4.7( \pm 1.1)$ & $4.8( \pm 0.8)$ & $2.2( \pm 0.9)$ & $11.7( \pm 2.1)$ & 11. $0( \pm 5.1)$ \\
\hline Partial hip replacement & $23(11 \%)$ & $4.6( \pm 1.2)$ & $4.3( \pm 0.9)$ & $1.4( \pm 0.9)$ & $10.3( \pm 1.6)$ & $11.3( \pm 5.2)$ \\
\hline \multicolumn{7}{|l|}{ Mobilization } \\
\hline Early & $122(60 \%)$ & $4.1( \pm 0.9)$ & $4.4( \pm 0.8)$ & $1.5( \pm 0.9)$ & $10.1( \pm 1.8)$ & $9.4( \pm 5.3)$ \\
\hline Late & $81(40 \%)$ & $4.1( \pm 1.1)$ & $4.4( \pm 0.9)$ & $1.6( \pm 1.0)$ & $10.1( \pm 2.1)$ & $10.5( \pm 5.0)$ \\
\hline \multicolumn{7}{|l|}{ Weight bearing } \\
\hline Full & $145(71 \%)$ & $4.1( \pm 0.9)$ & $4.4( \pm 0.9)$ & $1.6( \pm 0.9)$ & $10.1( \pm 1.9)$ & $9.5( \pm 5.2)$ \\
\hline Partial & $58(29 \%)$ & $4.1( \pm 1.1)$ & $4.4( \pm 0.7)$ & $1.6( \pm 0.9)$ & $10.0( \pm 2.0)$ & $10.8( \pm 5.2)$ \\
\hline \multicolumn{7}{|l|}{ ASA } \\
\hline $\mathrm{I} / \mathrm{II}$ & $83(41 \%)$ & $4.2( \pm 1.0)$ & $4.4( \pm 0.8)$ & $1.8( \pm 1.0)$ & $10.4( \pm 2.0)$ & $9.7( \pm 4.9)$ \\
\hline III/IV & $120(59 \%)$ & $4.0( \pm 1.0)$ & $4.4( \pm 0.9)$ & $1.4( \pm 0.9)$ & $9.9( \pm 1.8)$ & $10.0( \pm 5.4)$ \\
\hline
\end{tabular}

ASA, American Society of Anesthesiologist Physical Status classification; $n$, numbers.

Table 4. Predictors for pain.

\begin{tabular}{|c|c|c|c|c|c|c|}
\hline & \multirow{2}{*}{$\frac{\text { Unstandardized coefficients }}{B}$} & \multirow{2}{*}{$\frac{\text { Standardized coefficients }}{\text { Beta }}$} & \multirow[t]{2}{*}{$t$} & \multirow[t]{2}{*}{ Sig. } & \multicolumn{2}{|c|}{$95 \% \mathrm{CI}$} \\
\hline & & & & & Lower & Upper \\
\hline$\overline{\text { Age }}$ & 0.002 & 0.012 & 0.167 & 0.867 & -0.018 & 0.022 \\
\hline Gender & -0.017 & -0.008 & -0.113 & 0.910 & -0.314 & 0.280 \\
\hline Fracture type & 0.542 & 0.246 & 1.395 & 0.165 & -0.224 & 1.309 \\
\hline Fracture treatment & 0.139 & 0.095 & 0.543 & 0.588 & -0.366 & 0.643 \\
\hline ASA & -0.154 & -0.077 & -1.067 & 0.287 & -0.439 & 0.131 \\
\hline Mobilization & 0.109 & 0.054 & 0.771 & 0.441 & -0.170 & 0.387 \\
\hline Weight bearing & -0.076 & -0.035 & -0.499 & 0.619 & -0.379 & 0.226 \\
\hline
\end{tabular}

Dependent variable: Pain (0-6).

Predictors: (Constant), Weight bearing, Gender, Fracture type, ASA Low/High, Mobilization, Age, Fracture treatment.

Table 5. Predictors for mobility.

\begin{tabular}{|c|c|c|c|c|c|c|}
\hline & \multirow{2}{*}{$\frac{\text { Unstandardized coefficients }}{B}$} & \multirow{2}{*}{$\frac{\text { Standardized coefficients }}{\text { Beta }}$} & \multirow[t]{2}{*}{$t$} & \multirow[t]{2}{*}{ Sig. } & \multicolumn{2}{|c|}{$95 \% \mathrm{CI}$} \\
\hline & & & & & Lower & Upper \\
\hline$\overline{\text { Age }}$ & -0.001 & -0.005 & -0.066 & 0.948 & -0.018 & 0.017 \\
\hline Gender & 0.036 & 0.020 & 0.275 & 0.783 & -0.223 & 0.295 \\
\hline Fracture type & 1.061 & 0.568 & 3.128 & 0.002 & 0.392 & 1.729 \\
\hline Fracture treatment & -0.535 & -0.434 & -2.399 & 0.018 & -0.975 & -0.095 \\
\hline ASA & 0.051 & 0.030 & 0.401 & 0.689 & -0.198 & 0.299 \\
\hline Mobilization & 0.077 & 0.045 & 0.628 & 0.531 & -0.166 & 0.320 \\
\hline Weight bearing & 0.043 & 0.023 & 0.322 & 0.748 & -0.221 & 0.307 \\
\hline
\end{tabular}

Dependent variable: Mobility (0-6).

Predictors: (Constant), Weight bearing, Gender, Fracture type, ASA Low/High, Mobilization, Age, Fracture treatment.

\section{Mortality}

The in-hospital mortality rate in our study is $7.3 \%$. This is consistent with international studies which showed in-hospital mortality rates between 3 and 10\% [13,16,28-31]. In addition, ASA score has been previously found to have an influence on mortality after a fracture of the hip [14,23,32]. In our cohort, a short time to first mobilization is associated with a lower 
Table 6. Predictors for ability to walk.

\begin{tabular}{|c|c|c|c|c|c|c|}
\hline & \multirow{2}{*}{$\frac{\text { Unstandardized coefficients }}{B}$} & \multirow{2}{*}{$\frac{\text { Standardized coefficients }}{\text { Beta }}$} & \multirow[t]{2}{*}{$t$} & \multirow[t]{2}{*}{ Sig. } & \multicolumn{2}{|c|}{$95 \% \mathrm{CI}$} \\
\hline & & & & & Lower & Upper \\
\hline$\overline{\text { Age }}$ & -0.033 & -0.255 & -3.606 & $<0.001$ & -0.051 & -0.015 \\
\hline Gender & -0.058 & -0.029 & -0.423 & 0.673 & -0.329 & 0.213 \\
\hline Fracture type & 0.690 & 0.337 & 1.944 & 0.053 & -0.010 & 1.389 \\
\hline Fracture treatment & -0.314 & -0.232 & -1.346 & 0.180 & -0.775 & 0.146 \\
\hline ASA & -0.289 & -0.155 & -2.191 & 0.030 & -0.549 & -0.029 \\
\hline Mobilization & -0.068 & -0.036 & -0.528 & 0.598 & -0.322 & 0.186 \\
\hline Weight bearing & -0.135 & -0.066 & -0.964 & 0.336 & -0.411 & 0.141 \\
\hline
\end{tabular}

Dependent variable: Ability to walk (0-6).

Predictors: (Constant), Weight bearing, Gender, Fracture type, ASA Low/High, Mobilization, Age, Fracture treatment.

Table 7. Predictors for Merle d'Aubigné score.

\begin{tabular}{|c|c|c|c|c|c|c|}
\hline & \multirow{2}{*}{$\frac{\text { Unstandardized coefficients }}{B}$} & \multirow{2}{*}{$\frac{\text { Standardized coefficients }}{\text { Beta }}$} & \multirow[t]{2}{*}{$t$} & \multirow[t]{2}{*}{ Sig. } & \multicolumn{2}{|c|}{$95 \% \mathrm{CI}$} \\
\hline & & & & & Lower & Upper \\
\hline$\overline{\text { Age }}$ & -0.032 & -0.119 & -1.690 & 0.093 & -0.070 & 0.005 \\
\hline Gender & -0.039 & -0.009 & -0.137 & 0.891 & -0.597 & 0.520 \\
\hline Fracture type & 2.293 & 0.541 & 3.133 & 0.002 & 0.849 & 3.736 \\
\hline Fracture treatment & -0.711 & -0.254 & -1.476 & 0.142 & -1.660 & 0.239 \\
\hline ASA & -0.393 & -0.101 & -1.443 & 0.151 & -0.929 & 0.144 \\
\hline Mobilization & 0.118 & 0.030 & 0.444 & 0.657 & -0.406 & 0.642 \\
\hline Weight bearing & -0.168 & -0.040 & -0.583 & 0.561 & -0.737 & 0.401 \\
\hline
\end{tabular}

Dependent variable: Merle d'Aubigné (0-18).

Predictors: (Constant), Weight bearing, Gender, Fracture type, ASA Low/High, Mobilization, Age, Fracture treatment.

Table 8. Predictors for length of stay (in days).

\begin{tabular}{|c|c|c|c|c|c|c|}
\hline & \multirow{2}{*}{$\frac{\text { Unstandardized coefficients }}{B}$} & \multirow{2}{*}{$\frac{\text { Standardized coefficients }}{\text { Beta }}$} & \multirow[t]{2}{*}{$t$} & \multirow[t]{2}{*}{ Sig. } & \multicolumn{2}{|c|}{$95 \% \mathrm{CI}$} \\
\hline & & & & & Lower & Upper \\
\hline$\overline{\text { Age }}$ & -0.026 & -0.035 & -0.472 & 0.637 & -0.133 & 0.081 \\
\hline Gender & 1.945 & 0.173 & 2.413 & 0.017 & 0.355 & 3.534 \\
\hline Fracture type & 0.540 & 0.047 & 0.259 & 0.796 & -3.567 & 4.647 \\
\hline Fracture treatment & 0.510 & 0.067 & 0.373 & 0.710 & -2.192 & 3.213 \\
\hline ASA & -0.111 & -0.011 & -0.143 & 0.886 & -1.639 & 1.417 \\
\hline Mobilization & -0.720 & -0.068 & -0.951 & 0.343 & -2.212 & 0.772 \\
\hline Weight bearing & 1.087 & 0.095 & 1.324 & 0.187 & -0.532 & 2.707 \\
\hline
\end{tabular}

Dependent Variable: Lengh of stay (in days).

Predictors: (Constant), Weight bearing, Gender, Fracture type, ASA Low/High, Mobilization, Age, Fracture treatment.

mortality rate. This is consistent with Siu et al.; they showed that prolonged immobility was associated with higher mortality rates at six months [33]. Still, the association of early mobilization and lower mortality rate seems not to be very surprising, since early ambulation has been shown to have less complication and, therefore, in connection lower mortality. In our cohort, there is a threshold of $24 \mathrm{~h}$ between operation and first mobilization.

\section{Complications}

We found less complication in patients mobilized in the first $24 \mathrm{~h}$ after operation than in patients mobilized later than 24 or
48 h. This is comparable with previous studies [6-9]. At the same time, lower ASA and female gender were associated with lower complication rates. This has been shown in many different studies, which analyzed preoperative patient characteristics with in-hospital or long-term outcome [16,34]. The question remains the causality.

\section{Pain}

The level of pain was higher in trochanteric fractures and patients treated with an intramedullary nail. This is consistent with international studies $[18,35,36]$. In contrast to these studies, we found no negative influence of pain on the ability of 
early mobilization $[18,35,36]$. This may be due to our orthogeriatric concept of intense physiotherapy and pain management. At least, early mobilization and full-weight bearing did not increase the level of pain.

We found no negative predictors for pain; however we only analyzed several factors. Besides fracture type and fracture treatment, a short time to fracture treatment, the mental health status or depression have been identified as a predictor for pain in different studies [1,7]. The focus in treating hip fracture patients must be an adequate pain management, especially in patients with trochanteric fractures, and a short time to fracture treatment.

\section{Mobility of the hip}

Ninety percent of our patients reached a mobility score of four or higher at the end of the hospital stay. In other words, only $10 \%$ were not able to reach their feet. Fracture type and treatment were predictors for hip mobility, but early mobilization and full weight bearing had no influence on hip mobility.

Different assessment tools have been used to evaluate the functional outcome after surgery of the hip. In this study we used the Merle d'Aubigné score, which contains the mobility of the hip score. Since nearly all patients, independent of our confounders, had the same mobility of the hip score, this mobility of the hip score seems inadequate to be used for this purpose. The cumulative ambulation score (CAS) seems to be more useful in the clinical context. It evaluates specific motion sequences like getting in and out of bed or sit to stand from a chair over the first three postoperative days.

\section{Ability to walk}

In this study group, only $3 \%$ of the patients were able to walk without crutches for a short distance. Forty one percent of the patients were able to walk with crutches. This seems to be low compared with other studies reporting 53-80\% of patients reaching pre-injury functional level [28,30,31]. Early mobilization and full weight bearing did not have any effect on the mobility of the hip and ability to walk until discharge. Nevertheless, since it is common in Switzerland for elderly patients with hip fracture to enter a rehabilitation facility or nursing home before reaching their preoperative state, the ability to walk should be compared after rehabilitation.

Full weight bearing seems to be favored and associated with a better functional outcome [22,24]. In addition, orthogeriatric patients might have problems to follow a partial weight bearing protocol depending on their overall health status. In this context, a higher ASA-Score and a higher age were the only predictors for a lower ability to walk in our study population. This is consistent with other studies [13,14,23,32].

\section{Conclusions}

This study emphasizes the importance of early mobilization after a surgical hip procedure to reduce complications and death. It showed also reproducible risk factors for a negative in-hospital outcome, such as higher age and higher ASA score.
Early mobilization and weight bearing did yet not have any short-term effect on pain, mobility of the hip, and ability to walk in our cohort. Fracture type and fracture treatment mainly influenced the in-hospital functional outcome.

\section{Conflict of interest}

There are no conflicts of interest.

\section{References}

1. Alexiou KI, Roushias A, Varitimidis SE, Malizos KN (2018) Quality of life and psychological consequences in elderly patients after a hip fracture: a review. Clin Interv Aging 13, 143-150.

2. Brenneman SK, Barrett-Connor E, Sajjan S, Markson LE, Siris ES (2006) Impact of recent fracture on health-related quality of life in postmenopausal women. J Bone Miner Res 21, 809-816.

3. Pareja Sierra T, Bartolome Martin I, Rodriguez Solis J, Barcena Goitiandia L, Gonzalez Torralba, de Suso M, Morales Sanz MD, Hornillos Calvo M (2017) Predictive factors of hospital stay, mortality and functional recovery after surgery for hip fracture in elderly patients. Rev Esp Cir Ortop Traumatol 61, 427-435.

4. Yoo JI, Ha YC, Lim JY, Kang H, Yoon BH, Kim H (2017) Early Rehabilitation in Elderly after Arthroplasty versus Internal Fixation for Unstable Intertrochanteric Fractures of Femur: Systematic Review and Meta-Analysis. J Korean Med Sci 32, 858-867.

5. Rapp K, Rothenbacher D, Magaziner J, Becker C, Benzinger P, Konig HH, Jaensch A, Buchele G (2015) Risk of Nursing Home Admission After Femoral Fracture Compared With Stroke, Myocardial Infarction, and Pneumonia. J Am Med Dir Assoc 16, 715.e7-715.e12.

6. Laflamme GY, Rouleau DM, Leduc S, Roy L, Beaumont E (2012) The Timed Up and Go test is an early predictor of functional outcome after hemiarthroplasty for femoral neck fracture. J Bone Joint Surg Am 94, 1175-1179.

7. Oldmeadow LB, Edwards ER, Kimmel LA, Kipen E, Robertson VJ, Bailey MJ (2006) No rest for the wounded: early ambulation after hip surgery accelerates recovery. ANZ J Surg Australia 76(7), 607-611.

8. Kamel HK, Iqbal MA, Mogallapu R, Maas D, Hoffmann RG (2003) Time to ambulation after hip fracture surgery: relation to hospitalization outcomes. J Gerontol A Biol Sci Med Sci 58, 1042-1045.

9. Sanguineti VA, Wild JR, Fain MJ (2014) Management of postoperative complications: general approach. Clin Geriatr Med 30, 261-270.

10. Kim SM, Moon YW, Lim SJ, Yoon BK, Min YK, Lee DY, Park YS (2012) Prediction of survival, second fracture, and functional recovery following the first hip fracture surgery in elderly patients. Bone 50, 1343-1350.

11. Morri M, Forni C, Marchioni M, Bonetti E, Marseglia F, Cotti A (2018) Which factors are independent predictors of early recovery of mobility in the older adults' population after hip fracture? A cohort prognostic study. Arch Orthop Trauma Surg Germany 138(1), 35-41.

12. Kristensen MT, Kehlet H (2018) The basic mobility status upon acute hospital discharge is an independent risk factor for mortality up to 5 years after hip fracture surgery. Acta Orthop $89,47-52$. 
13. Bliemel C, Buecking B, Oberkircher L, Knobe M, Ruchholtz S, Eschbach D (2017) The impact of pre-existing conditions on functional outcome and mortality in geriatric hip fracture patients. Int Orthop 42(10), 1995-2000.

14. Holt G, Macdonald D, Fraser M, Reece AT (2006) Outcome after surgery for fracture of the hip in patients aged over 95 years. J Bone Joint Surg Br 88, 1060-1064.

15. Endo Y, Aharonoff GB, Zuckerman JD, Egol KA, Koval KJ (2005) Gender differences in patients with hip fracture: a greater risk of morbidity and mortality in men. J Orthop Trauma 19, 29-35.

16. Eastwood EA, Magaziner J, Wang J, Silberzweig SB, Hannan EL, Strauss E, Siu AL (2002) Patients with hip fracture: subgroups and their outcomes. J Am Geriatr Soc 50, 1240-1249.

17. Beaupre LA, Binder EF, Cameron ID, Jones CA, Orwig D, Sherrington C, Magaziner J (2013) Maximising functional recovery following hip fracture in frail seniors. Best Pract Res Clin Rheumatol 27, 771-788.

18. Munter KH, Clemmesen CG, Foss NB, Palm H, Kristensen MT (2017) Fatigue and pain limit independent mobility and physiotherapy after hip fracture surgery. Disabil Rehabil 40(15), 1808-1816.

19. Zhang J, Ang ML, Kwek EB (2015) Who Will Walk Again? Effects of Rehabilitation on the Ambulatory Status in Elderly Patients Undergoing Hemiarthroplasty for Femoral Neck Fracture. Geriatr Orthop Surg Rehabil 6, 168-172.

20. Stenvall M, Olofsson B, Nyberg L, Lundstrom M, Gustafson Y (2007) Improved performance in activities of daily living and mobility after a multidisciplinary postoperative rehabilitation in older people with femoral neck fracture: a randomized controlled trial with 1-year follow-up. J Rehabil Med 39, 232-238.

21. Davison J, Bond J, Dawson P, Steen IN, Kenny RA (2005) Patients with recurrent falls attending Accident \& Emergency benefit from multifactorial intervention-a randomised controlled trial. Age Ageing 34, 162-168.

22. Ariza-Vega P, Jimenez-Moleon JJ, Kristensen MT (2014) Non-weight-bearing status compromises the functional level up to 1 yr after hip fracture surgery. Am J Phys Med Rehabil 93, 641-648.

23. Ariza-Vega P, Kristensen MT, Martin-Martin L, JimenezMoleon JJ (2015) Predictors of long-term mortality in older people with hip fracture. Arch Phys Med Rehabil 96, 1215-1221.
24. Wu J, Kurrle S, Cameron ID (2009) Restricted weight bearing after hip fracture surgery in the elderly: economic costs and health outcomes. J Eval Clin Pract 15(1), 217-219.

25. Siebens HC, Sharkey P, Aronow HU, Horn SD, Munin MC, DeJong G, Smout RJ, Radnay CS (2012) Outcomes and weightbearing status during rehabilitation after arthroplasty for hip fractures. PM R 4(8), 548-555.

26. Owens WD, Felts JA, Spitznagel EL Jr (1978) ASA physical status classifications: a study of consistency of ratings. Anesthesiology 49, 239-243.

27. d'Aubigne RM, Postel M (2009) The classic: functional results of hip arthroplasty with acrylic prosthesis.1954. Clin Orthop Relat Res 467, 7-27.

28. Intiso D, Di Rienzo F, Grimaldi G, Lombardi T, Fiore P, Maruzzi G, Iarossi A, Tolfa M, Pazienza L (2009) Survival and functional outcome in patients 90 years of age or older after hip fracture. Age Ageing 38, 619-622.

29. Miller AG, Bercik MJ, Ong A (2012) Nonagenarian hip fracture: treatment and complications. J Trauma Acute Care Surg 72, 1411-1415.

30. Shah MR, Aharonoff GB, Wolinsky P, Zuckerman JD, Koval $\mathrm{KJ}$ (2001) Outcome after hip fracture in individuals ninety years of age and older. J Orthop Trauma 15, 34-39.

31. Formiga F, Lopez-Soto A, Sacanella E, Coscojuela A, Suso S, Pujol R (2003) Mortality and morbidity in nonagenarian patients following hip fracture surgery. Gerontology 49, 41-45.

32. Chen LH, Liang J, Chen MC, Wu CC, Cheng HS, Wang HH, Shyu YL (2017) The relationship between preoperative American Society of Anesthesiologists Physical Status Classification scores and functional recovery following hip-fracture surgery. BMC Musculoskelet Disord 18, 410.

33. Siu AL, Penrod JD, Boockvar KS, Koval K, Strauss E, Morrison RS (2006) Early ambulation after hip fracture: effects on function and mortality. Arch Intern Med 166, 766-771.

34. Donegan DJ, Gay AN, Baldwin K, Morales EE, Esterhai JL Jr, Mehta S (2010) Use of medical comorbidities to predict complications after hip fracture surgery in the elderly. J Bone Joint Surg Am 92, 807-813.

35. Foss NB, Kristensen MT, Palm H, Kehlet H (2009) Postoperative pain after hip fracture is procedure specific. $\mathrm{Br} \mathbf{J}$ Anaesth 102, 111-116.

36. Kristensen MT (2013) Hip fracture-related pain strongly influences functional performance of patients with an intertrochanteric fracture upon discharge from the hospital. PM R 5, $135-141$. 